\title{
Trend Analysis of Vital Statistics in India - A Key to Improve Quality of Health Care Services and Infrastructure
}

\author{
Suganya. $P^{1}$, Bharathwaj. V. $V^{2}$, Sindhu. $R^{2}$, Dinesh Dhamodhar ${ }^{3}$, \\ Shreelakshmi. S ${ }^{2}$, Prabu. ${ }^{4}$, Rajmohan. $\mathbf{M}^{3}$, Prashanthy. M. ${ }^{1}$ \\ ${ }^{1}$ Postgraduate Student, Department of Public Health Dentistry, SRM Dental College and Hospital, Ramapuram \\ ${ }^{2}$ Senior Lecturer, Department of Public Health Dentistry, SRM Dental College and Hospital, Ramapuram \\ ${ }^{3}$ Reader, Department of Public Health Dentistry, SRM Dental College and Hospital, Ramapuram \\ ${ }^{4}$ Head and Professor of the Department, Department of Public Health Dentistry, SRM Dental College and \\ Hospital, Ramapuram \\ Corresponding Author: Prabu. D
}

\section{ABSTRACT}

Aim: The aim of this study is to assess the trends of vital statistics in India for improving the quality of health care services and infrastructure.

Materials and Methods: This study was carried out to improve the quality of health care services and infrastructure by analysing the trends of vital statistics in India. The data regarding vital statistics which includes birth rate, death rate, infant mortality rate, neonatal mortality rate and total fertility rate were obtained from the year 2011-2017 using electronic sources such as sample registration system, National health profile and NITI Aayog. Results: The death rate found to be increased in various states and union territories of India. Over all the states and union territories in India Chhattisgarh, Madhya Pradesh, Odisha, Assam, Puducherry, Punjab and Uttar Pradesh has the highest death rate whereas the Nagaland, Chandigarh and Delhi has the lowest death rate. The rural areas of India have the highest number of mortality rate when compared to urban areas.

Conclusion: The government of India should pay more attention to the health care services and increase the health care expenditure of the public from the Gross Domestic Product (GDP) for the beneficiaries of people.

Keywords: Trend analysis, Vital statistics, India, Gross Domestic Product, Health care services, Infrastructure.

\section{INTRODUCTION}

India is one of the seventh largest country in the world which covers an area of 32, 87, 263 sq.km. It ranks second place with the highest number of populations over the world. As per Census 2011, the total population of India is 1210.8 million with a decadal growth rate of 17.7 per cent, where 31.14 per cent of the population lives in urban areas, the rest lives in rural areas. In the year 2017, the total number of populations is 1,316.9 million. Currently, the status of population in India is estimated as 1.37 billion or 1,369 millions with a growth rate of $1.08 \%{ }^{1}$.

The good health and well-being are of utmost important than anything in the world and it plays a pivotal role in leading a better quality of life. Many factors influence health status and a country's ability to provide quality health services for its people. WHO provides a greater support in developing health care facilities and policies and it also supports the government for greater level of health investments in order to ensure that health prioritized overall anything ${ }^{2}$.

Vital statistics plays a crucial role in quantifying and indicating the health issues to ensure further improvement in the quality of health care facilities by providing a 
Suganya. P et.al. Trend analysis of vital statistics in India - a key to improve quality of health care services and infrastructure.

cumulative data regarding birth rate, death rate, infant mortality rate, neonatal mortality rate and maternal mortality rate. It ensures the government to achieve public health goals by developing the standard health care facilities ${ }^{3}$.

The trend analysis of vital statistics helps the government and health care professionals to identify the exact root cause of the health-related problems and help them to rectify the issues by formulating policies for providing public health policies and social security to the public ${ }^{3}$.

However, no studies have been conducted based on the trend analysis of vital statistics for improving the quality of health care services and infrastructure. Considering the beneficiaries of vital statistics in health care management, it would be meaningful to analyze the history and trends of research conducted over the vital statistics. Hence in this study the data related to vital statistics between the years 2011-2017 were assessed using sample registration system with the aim of revealing trend analysis to improve the quality of health care services and infrastructure in India.

\section{MATERIALS AND METHODS}

The study was conducted to evaluate the trend analysis of vital statistics in India from the year 2011-2017. The vital statistics parameters include birth rate, death rate, infant mortality rate, neonatal mortality rate and total fertility rate are assessed

The data were recruited from various electronic sources such as sample registration system (SRS), National health profile and NITI Aayog 4, 5, 6, 7, 8 . The vital statistics from the various zones of India which includes north zone, west zone, east zone, south zone, central zone and north east zone were analyzed and the vital statistics from the rural and urban areas were tabulated accordingly from the year 2011-2017.

The inclusion criteria are only data from the year 2011- 2017 were obtained and only available data were collected. The data which are not clear and obvious are excluded from the study.

\section{RESULT}

TABLE 1: VITAL STATISTICS IN NORTH ZONE OF INDIA

\begin{tabular}{|c|c|c|c|c|c|c|c|c|}
\hline STATES AND UNION TERRITORIES & PARAMETERS & 2011 & 2012 & 2013 & 2014 & 2015 & 2016 & 2017 \\
\hline \multirow[t]{5}{*}{ Jammu and Kashmir } & Birth rate & 16.5 & 16.2 & 16.0 & $* 16.4$ & 16.3 & 16.0 & 15.8 \\
\hline & Death rate & 5.5 & 5.4 & 5.3 & 5.1 & 4.9 & $* 5.0$ & 4.8 \\
\hline & Infant mortality rate & 41 & 39 & 37 & 34 & 26 & 24 & 23 \\
\hline & Neonatal mortality rate & 32 & 30 & 29 & 26 & 20 & 18 & 17 \\
\hline & Total fertility rate & 1.9 & 1.9 & 1.9 & 1.7 & 1.6 & $* 1.7$ & 1.6 \\
\hline \multirow[t]{5}{*}{ Himachal Pradesh } & Birth rate & 16.5 & 16.2 & 16.0 & 16.4 & 16.3 & 16.0 & 15.8 \\
\hline & Death rate & 6.7 & 6.7 & 6.7 & 6.7 & 6.6 & $* 6.8$ & 6.6 \\
\hline & Infant mortality rate & 38 & 36 & 35 & 32 & 28 & 25 & 22 \\
\hline & Neonatal mortality rate & 28 & 26 & 25 & 25 & 19 & 16 & 14 \\
\hline & Total fertility rate & 1.8 & 1.7 & 1.7 & 1.7 & 1.7 & 1.7 & 1.6 \\
\hline \multirow[t]{5}{*}{ Punjab } & Birth rate & 16.2 & 15.9 & 15.7 & 15.5 & 15.2 & 14.9 & 14.9 \\
\hline & Death rate & 6.8 & 6.8 & 6.7 & 6.4 & 6.2 & 6.0 & $* 7.0$ \\
\hline & Infant mortality rate & 30 & 28 & 26 & 24 & 23 & 21 & 21 \\
\hline & Neonatal mortality rate & 24 & 17 & 16 & 14 & 13 & 13 & 13 \\
\hline & Total fertility rate & 1.8 & 1.7 & 1.7 & 1.7 & 1.7 & 1.7 & 1.6 \\
\hline \multirow[t]{5}{*}{ Uttarakhand } & Birth rate & 18.9 & 18.5 & 18.2 & 18.2 & 17.8 & 16.6 & $* 17.3$ \\
\hline & Death rate & 6.2 & 6.1 & 6.1 & 6.0 & 6.4 & $* 6.7$ & 6.7 \\
\hline & Infant mortality rate & 36 & 34 & 32 & 33 & 34 & 38 & 32 \\
\hline & Neonatal mortality rate & - & - & - & 26 & 28 & $* 30$ & 24 \\
\hline & Total fertility rate & 2.1 & 2.0 & 1.9 & 2.0 & 2.0 & 1.9 & 1.9 \\
\hline \multirow[t]{5}{*}{ Uttar Pradesh } & Birth rate & 27.8 & 27.4 & 27.2 & 27.0 & 26.7 & 26.2 & 25.9 \\
\hline & Death rate & 7.9 & 7.7 & 7.7 & 7.4 & 7.2 & 6.9 & 6.7 \\
\hline & Infant mortality rate & 57 & 53 & 50 & 48 & 46 & 43 & 41 \\
\hline & Neonatal mortality rate & 40 & 37 & 35 & 32 & 31 & 30 & 30 \\
\hline & Total fertility rate & 3.4 & 3.3 & 3.1 & 3.2 & 3.1 & 3.1 & 3.0 \\
\hline \multirow[t]{5}{*}{ Haryana } & Birth rate & 21.8 & 21.6 & 21.3 & 21.2 & 20.9 & 20.7 & 20.5 \\
\hline & Death rate & 6.5 & 6.4 & 6.3 & 6.1 & 6.1 & 5.9 & 5.8 \\
\hline & Infant mortality rate & 44 & 42 & 41 & 36 & 36 & 33 & 30 \\
\hline & Neonatal mortality rate & 28 & 28 & 26 & 23 & 24 & 22 & 21 \\
\hline & Total fertility rate & 2.3 & 2.3 & 2.2 & 2.3 & 2.2 & 2.3 & 2.2 \\
\hline
\end{tabular}


Suganya. P et.al. Trend analysis of vital statistics in India - a key to improve quality of health care services and infrastructure.

\begin{tabular}{|l|l|l|l|l|l|l|l|l|}
\hline \multicolumn{4}{|c|}{ Table 1 Continued... } & \multicolumn{1}{l|}{} \\
\hline \multirow{4}{*}{ Delhi } & Birth rate & 17.5 & 17.3 & 17.2 & 16.8 & 16,4 & 15.5 & 15.2 \\
\cline { 2 - 9 } & Death rate & 4.3 & 4.2 & 4.1 & 3.8 & 3.6 & $* 4.0$ & 3.7 \\
\cline { 2 - 9 } & Infant mortality rate & 28 & 25 & 24 & 20 & 18 & 18 & 16 \\
\cline { 2 - 9 } & Neonatal mortality rate & 18 & 16 & 16 & 13 & 14 & 12 & 14 \\
\cline { 2 - 9 } & Total fertility rate & 1.8 & 1.9 & 1.7 & 1.7 & 1.7 & 1.6 & 1.5 \\
\hline \multirow{5}{*}{ Chandigarh } & Birth rate & 15.0 & 14.8 & 14.7 & 14.3 & 13.7 & $* 13.9$ & 13.5 \\
\cline { 2 - 9 } & Death rate & 4.1 & 4.0 & 4.0 & 4.0 & 4.4 & $* 4.5$ & 4.5 \\
\cline { 2 - 9 } & Infant mortality rate & 20 & 20 & 20 & 23 & 21 & 14 & 14 \\
\cline { 2 - 9 } & Neonatal mortality rate & - & - & - & - & - & - & - \\
\cline { 2 - 8 } & Total fertility rate & 1.6 & 1.6 & 1.5 & - & - & - & - \\
\hline
\end{tabular}

NOTE: (*highest rate of the vital statistics parameter)

Table 1 shows about the trend analysis of vital statistics in north zone of India. The birth rate, death rate, infant mortality rate, neonatal mortality rate was found to be highest in Uttar Pradesh. The lowest birth rate was found in Punjab whereas the death was lowest in Delhi. The total fertility rate was highest in Uttar Pradesh and it was lowest in Delhi and Himachal Pradesh among the north zone of India.

TABLE 2: VITAL STATISTICS IN EAST ZONE OF INDIA

\begin{tabular}{|c|c|c|c|c|c|c|c|c|}
\hline STATES AND UNION TERRITORIES & PARAMETERS & 2011 & 2012 & 2013 & 2014 & 2015 & 2016 & 2017 \\
\hline \multirow[t]{5}{*}{ Bihar } & Birth rate & 27.7 & 27.7 & 27.6 & 25.9 & 26.3 & *26.8 & 26.4 \\
\hline & Death rate & 6.7 & 6.6 & 6.6 & 6.2 & 6.2 & 6.0 & 5.8 \\
\hline & Infant mortality rate & 44 & 43 & 42 & 42 & 42 & 38 & 35 \\
\hline & Neonatal mortality rate & 29 & 28 & 28 & 27 & 28 & 27 & 28 \\
\hline & Total fertility rate & 3.6 & 3.5 & 3.4 & 3.2 & 3.2 & $* 3.3$ & 3.2 \\
\hline \multirow[t]{5}{*}{ Odisha } & Birth rate & 20.1 & 19.9 & 19.6 & 19.4 & 19.2 & 18.6 & 18.3 \\
\hline & Death rate & 8.5 & 8.5 & 8.4 & 7.9 & 7.6 & $* 7.8$ & 7.4 \\
\hline & Infant mortality rate & 57 & 53 & 51 & 49 & 46 & 44 & 41 \\
\hline & Neonatal mortality rate & 40 & 39 & 37 & 36 & 35 & 32 & 32 \\
\hline & Total fertility rate & 2.2 & 2.1 & 2.1 & 2.1 & 2.0 & 2.0 & 1.9 \\
\hline \multirow[t]{5}{*}{ Jharkhand } & Birth rate & 24.6 & 24.7 & 24.6 & 23.8 & 23.5 & 22.9 & 22.7 \\
\hline & Death rate & 6.9 & 6.8 & 6.8 & 5.9 & 5.8 & 5.5 & 5.5 \\
\hline & Infant mortality rate & 39 & 38 & 37 & 34 & 32 & 29 & 29 \\
\hline & Neonatal mortality rate & 29 & 27 & 26 & 25 & 23 & 21 & 20 \\
\hline & Total fertility rate & 2.9 & 2.8 & 2.7 & 2.8 & 2.7 & 2.6 & 2.5 \\
\hline \multirow[t]{5}{*}{ West Bengal } & Birth rate & 16.3 & 16,1 & 16.0 & 15.6 & 15.5 & 15.4 & 15.2 \\
\hline & Death rate & 6.2 & 6.3 & 6.4 & 6.1 & 5.9 & 5.8 & 5.8 \\
\hline & Infant mortality rate & 32 & 32 & 31 & 28 & 26 & 25 & 24 \\
\hline & Neonatal mortality rate & 22 & 22 & 21 & 19 & 18 & 17 & 17 \\
\hline & Total fertility rate & 1.7 & 1.7 & 1.6 & 1.6 & 1.6 & 1.6 & 1.6 \\
\hline
\end{tabular}

NOTE: (*highest rate of the vital statistics parameter)

Table 2 shows about the trend analysis of vital statistics in east zone of India. The birth rate and total fertility rate was found to be highest in Bihar whereas the death rate, infant mortality rate and neonatal mortality rate was found to be highest in Odisha. The west Bengal has the lowest birth rate, death rate, infant mortality rate, neonatal mortality rate when compared to the other states in eastern zone of India.

TABLE 3: VITAL STATISTICS IN WEST ZONE OF INDIA

\begin{tabular}{|c|c|c|c|c|c|c|c|c|}
\hline STATES AND UNION TERRITORIES & PARAMETERS & 2011 & 2012 & 2013 & 2014 & 2015 & 2016 & 2017 \\
\hline \multirow[t]{5}{*}{ Rajasthan } & Birth rate & 26.2 & 25.9 & 25.6 & 25.0 & 24.8 & 24.3 & 24.1 \\
\hline & Death rate & 6.7 & 6.6 & 6.5 & 6.4 & 6.3 & 6.1 & 6.0 \\
\hline & Infant mortality rate & 52 & 49 & 47 & 46 & 43 & 41 & 38 \\
\hline & Neonatal mortality rate & 37 & 35 & 32 & 32 & 30 & 28 & 27 \\
\hline & Total fertility rate & 3.0 & 2.9 & 2.8 & 2.8 & 2.7 & 2.7 & 2.6 \\
\hline \multirow[t]{5}{*}{ Gujarat } & Birth rate & 21.3 & 21.1 & 20.8 & 20.6 & 20.4 & 20.1 & 19.9 \\
\hline & Death rate & 6.7 & 6.6 & 6.5 & 6.2 & 6.1 & 6.1 & $* 6.2$ \\
\hline & Infant mortality rate & 41 & 38 & 36 & 35 & 33 & 30 & 30 \\
\hline & Neonatal mortality rate & 30 & 28 & 26 & 24 & 23 & 21 & 21 \\
\hline & Total fertility rate & 2.4 & 2.3 & 2.3 & 2.3 & 2.2 & 2.2 & 2.2 \\
\hline \multirow[t]{5}{*}{ Goa } & Birth rate & 13.3 & 13.1 & 13.0 & 12.9 & 12.7 & $* 12.9$ & 12.5 \\
\hline & Death rate & 6.7 & 6.6 & 6.6 & 6.6 & 6.4 & $* 6.7$ & 6.2 \\
\hline & Infant mortality rate & 11 & 10 & 9 & 10 & 9 & 8 & $* 9$ \\
\hline & Neonatal mortality rate & - & - & - & - & - & - & - \\
\hline & Total fertility rate & 1.4 & 1.4 & 1.4 & - & - & - & - \\
\hline
\end{tabular}


Suganya. P et.al. Trend analysis of vital statistics in India - a key to improve quality of health care services and infrastructure.

\begin{tabular}{|c|c|c|c|c|c|c|c|c|}
\hline \multicolumn{9}{|c|}{ Table 3 Continued... } \\
\hline \multirow[t]{5}{*}{ Maharashtra } & Birth rate & 16.7 & 16.6 & 16.5 & 16.5 & 16.3 & 15.9 & 15.7 \\
\hline & Death rate & 6.3 & 6.3 & 6.2 & 6.0 & 5.8 & $* 5.9$ & 5.7 \\
\hline & Infant mortality rate & 25 & 25 & 24 & 22 & 21 & 19 & 19 \\
\hline & Neonatal mortality rate & 18 & 18 & 17 & 16 & 15 & 13 & 13 \\
\hline & Total fertility rate & 1.8 & 1.8 & 1.8 & 1.8 & 1.8 & 1.8 & 1.7 \\
\hline \multirow[t]{5}{*}{ Dadra and Nagar Haveli } & Birth rate & 26.1 & 25.6 & 25.5 & 25.6 & 25.5 & 24.5 & 23.6 \\
\hline & Death rate & 4.6 & 4.5 & 4.4 & 4.2 & 3.9 & $* 4.0$ & $* 4.4$ \\
\hline & Infant mortality rate & 35 & 33 & 31 & 26 & 21 & 17 & 13 \\
\hline & Neonatal mortality rate & - & - & - & - & - & - & - \\
\hline & Total fertility rate & 2.8 & 2.8 & 2.7 & - & - & - & \\
\hline \multirow[t]{5}{*}{ Daman and Diu } & Birth rate & 18.4 & 18.1 & 17.9 & 17.3 & 17.1 & $* 24.0$ & 20.2 \\
\hline & Death rate & 4.9 & 4.8 & 4.9 & 4.6 & $* 4.7$ & 4.6 & $* 4.7$ \\
\hline & Infant mortality rate & 22 & 22 & 20 & 18 & 18 & $* 19$ & 17 \\
\hline & Neonatal mortality rate & - & - & - & - & - & - & - \\
\hline & Total fertility rate & 2.0 & 2.0 & 1.9 & - & - & - & \\
\hline
\end{tabular}

NOTE: (*highest rate of the vital statistics parameter)

Table 3 shows about the trend analysis of vital statistics in west zone of India. The birth rate, infant mortality rate, neonatal mortality rate and total fertility rate was found to be highest in Rajasthan. The death rate was found to be highest in Gujarat whereas it was lowest in Dadra and Nagar Haveli.

TABLE 4: VITAL STATISTICS IN SOUTH ZONE OF INDIA

\begin{tabular}{|c|c|c|c|c|c|c|c|c|}
\hline STATES AND UNION TERRITORIES & PARAMETERS & 2011 & 2012 & 2013 & 2014 & 2015 & 2016 & 2017 \\
\hline \multirow[t]{5}{*}{ Andhra Pradesh } & Birth rate & 17.5 & 17.5 & 17.4 & 17.0 & 16.8 & 16.4 & 16.2 \\
\hline & Death rate & 7.5 & 7.4 & 7.3 & 7.3 & 7.1 & 6.8 & $* 7.2$ \\
\hline & Infant mortality rate & 43 & 41 & 39 & 39 & 37 & 34 & 32 \\
\hline & Neonatal mortality rate & 28 & 27 & 25 & 26 & 24 & 23 & 23 \\
\hline & Total fertility rate & 1.8 & 1.8 & 1.8 & 1.8 & 1.7 & 1.7 & 1.6 \\
\hline \multirow[t]{5}{*}{ Karnataka } & Birth rate & 18.8 & 18.5 & 18.3 & 18.1 & 17.9 & 17.6 & 17.4 \\
\hline & Death rate & 7.1 & 7.1 & 7.0 & 6.8 & 6.6 & $* 6.7$ & 6.5 \\
\hline & Infant mortality rate & 35 & 32 & 31 & 29 & 28 & 24 & 25 \\
\hline & Neonatal mortality rate & 24 & 23 & 22 & 20 & 19 & 18 & 18 \\
\hline & Total fertility rate & 1.9 & 1.9 & 1.9 & 1.8 & 1.8 & 1.8 & 1.7 \\
\hline \multirow[t]{5}{*}{ Kerala } & Birth rate & 15.2 & 14.9 & 14.7 & 14.8 & 14.8 & 14.3 & 14.2 \\
\hline & Death rate & 7.0 & 6.9 & 6.9 & 6.6 & 6.6 & $* 7.6$ & 6.8 \\
\hline & Infant mortality rate & 12 & 12 & 12 & 12 & 12 & 10 & 10 \\
\hline & Neonatal mortality rate & 7 & 7 & 6 & 6 & 6 & 6 & 5 \\
\hline & Total fertility rate & 1.8 & 1.8 & 1.8 & 1.9 & 1.8 & 1.8 & 1.7 \\
\hline \multirow[t]{5}{*}{ Tamil Nadu } & Birth rate & 15.9 & 15.7 & 15.6 & 15.4 & 15.2 & 15.0 & 14.9 \\
\hline & Death rate & 7.4 & 7.4 & 7.3 & 7.0 & 6.7 & 6.4 & $* 6.7$ \\
\hline & Infant mortality rate & 22 & 21 & 21 & 20 & 19 & 17 & 16 \\
\hline & Neonatal mortality rate & 15 & 15 & 15 & 14 & 14 & 12 & 11 \\
\hline & Total fertility rate & 1.7 & 1.7 & 1.7 & 1.7 & 1.6 & 1.6 & 1.6 \\
\hline \multirow[t]{5}{*}{ Telangana } & Birth rate & - & - & - & 18.0 & 17.8 & 17.5 & 17.2 \\
\hline & Death rate & - & - & - & 6.7 & 6.5 & 6.1 & $* 6.6$ \\
\hline & Infant mortality rate & - & - & - & 35 & 34 & 31 & 29 \\
\hline & Neonatal mortality rate & - & - & - & 25 & 23 & 21 & 20 \\
\hline & Total fertility rate & - & - & - & 1.8 & 1.8 & 1.7 & 1.7 \\
\hline \multirow[t]{5}{*}{ Lakshadweep } & Birth rate & 14.7 & 14.8 & 14.8 & 14.0 & 14.7 & 18.8 & 15.0 \\
\hline & Death rate & 6.4 & 6.4 & 6.3 & 6.1 & 6.2 & 6.0 & $* 6.5$ \\
\hline & Infant mortality rate & 24 & 24 & 24 & 20 & 20 & 19 & $* 20$ \\
\hline & Neonatal mortality rate & - & - & - & - & - & - & - \\
\hline & Total fertility rate & 1.6 & 1.6 & 1.6 & - & - & - & - \\
\hline \multirow[t]{5}{*}{ Puducherry } & Birth rate & 16.1 & 15,8 & 15.7 & 14.6 & 13.8 & $* 13.9$ & 13.2 \\
\hline & Death rate & 7.2 & 7.1 & 7.0 & 6.6 & 6.8 & $* 7.2$ & $* 7.3$ \\
\hline & Infant mortality rate & 22 & 19 & 17 & 14 & 11 & 10 & $* 11$ \\
\hline & Neonatal mortality rate & - & - & - & - & - & - & - \\
\hline & Total fertility rate & 1.7 & 1.7 & 1.7 & - & - & - & - \\
\hline \multirow[t]{5}{*}{ Andaman and Nicobar Island } & Birth rate & 15.1 & 15.0 & 14.6 & 14.7 & 12.0 & 11.7 & 11.4 \\
\hline & Death rate & 4.6 & 4.6 & 4.6 & 4.6 & 5.0 & $* 5.2$ & 5.1 \\
\hline & Infant mortality rate & 23 & 24 & 24 & 22 & 20 & 16 & 14 \\
\hline & Neonatal mortality rate & - & - & - & - & - & - & - \\
\hline & Total fertility rate & 0.7 & 0.8 & 0.7 & - & - & - & - \\
\hline
\end{tabular}

NOTE: (*highest rate of the vital statistics parameter) 
Suganya. P et.al. Trend analysis of vital statistics in India - a key to improve quality of health care services and infrastructure.

Table 4 shows about the trend analysis of vital statistics in south zone of India. The birth rate was found to be highest in Telangana whereas the death rate was found to be highest in Puducherry. The death rate was found to be lowest in Andaman and Nicobar Island

TABLE 5: VITAL STATISTICS IN CENTRAL ZONE OF INDIA

\begin{tabular}{|l|l|l|l|l|l|l|l|l|}
\hline STATES AND UNION TERRITORIES & PARAMETERS & $\mathbf{2 0 1 1}$ & $\mathbf{2 0 1 2}$ & $\mathbf{2 0 1 3}$ & $\mathbf{2 0 1 4}$ & $\mathbf{2 0 1 5}$ & $\mathbf{2 0 1 6}$ & $\mathbf{2 0 1 7}$ \\
\hline \multirow{4}{*}{ Madhya Pradesh } & Birth rate & 26.9 & 26.6 & 26.3 & 25.7 & 25.5 & 25.1 & 24.8 \\
\cline { 2 - 9 } & Death rate & 8.2 & 8.1 & 8.0 & 7.8 & 7.5 & 7.1 & 6.8 \\
\cline { 2 - 9 } & Infant mortality rate & 59 & 56 & 54 & 52 & 50 & 47 & 47 \\
\cline { 2 - 9 } & Neonatal mortality rate & 41 & 39 & 36 & 35 & 34 & 32 & $* 33$ \\
\cline { 2 - 9 } & Total fertility rate & 3.1 & 2.9 & 2.9 & 2.8 & 2.8 & 2.8 & 2.7 \\
\hline \multirow{5}{*}{ Chhattisgarh } & Birth rate & 24.9 & 24.5 & 24.4 & 23.4 & 23.2 & 22.8 & 22.7 \\
\cline { 2 - 9 } & Death rate & 7.9 & 7.9 & 7.9 & 7.7 & 7.5 & 7.4 & $* 7.5$ \\
\cline { 2 - 9 } & Infant mortality rate & 20 & 20 & 20 & 23 & 21 & 14 & 14 \\
\cline { 2 - 9 } & Neonatal mortality rate & 34 & 31 & 31 & 28 & 27 & 26 & 26 \\
\cline { 2 - 8 } & Total fertility rate & 2.7 & 2.7 & 2.6 & 2.6 & 2.5 & 2.5 & 2.4 \\
\hline
\end{tabular}

NOTE: (*highest rate of the vital statistics parameter)

Table 5 shows about the trend analysis of vital statistics in central zone of India. The birth rate, infant mortality rate, neonatal mortality rate and total fertility rate was found to highest in Madhya Pradesh whereas the death rate was found to be highest in Chhattisgarh in the year 2017.

TABLE 6: VITAL STATISTICS IN NORTH EAST ZONE OF INDIA

\begin{tabular}{|c|c|c|c|c|c|c|c|c|}
\hline STATES AND UNION TERRITORIES & PARAMETRES & 2011 & 2012 & 2013 & 2014 & 2015 & 2016 & 2017 \\
\hline \multirow[t]{5}{*}{ Assam } & Birth rate & 22.8 & 22.5 & 22.4 & 22.4 & 22.0 & $* 21.7$ & 21.2 \\
\hline & Death rate & 8.0 & 7.9 & 7.8 & 7.2 & 7.1 & 6.7 & 6.5 \\
\hline & Infant mortality rate & 55 & 55 & 54 & 49 & 47 & 44 & 44 \\
\hline & Neonatal mortality rate & 30 & 29 & 27 & 26 & 25 & 23 & 22 \\
\hline & Total fertility rate & 2.4 & 2.4 & 2.3 & 2.3 & 2.3 & 2.3 & 2.3 \\
\hline \multirow[t]{5}{*}{ Sikkim } & Birth rate & 17.6 & 17.2 & 17.1 & 17.1 & 17.0 & 16.6 & 16.4 \\
\hline & Death rate & 5.6 & 5.4 & 5.2 & 5.1 & 5.0 & 4.7 & 4.5 \\
\hline & Infant mortality rate & 26 & 24 & 22 & 19 & 18 & 16 & 12 \\
\hline & Neonatal mortality rate & - & - & - & - & - & - & - \\
\hline & Total fertility rate & 1.6 & 1.5 & 1.5 & - & - & - & - \\
\hline \multirow[t]{5}{*}{ Nagaland } & Birth rate & 16.1 & 15.6 & 15.4 & 15.3 & 14.8 & 14.0 & 13.5 \\
\hline & Death rate & 3.3 & 3.2 & 3.1 & 3.1 & 3.0 & $* 4.5$ & 3.6 \\
\hline & Infant mortality rate & 21 & 18 & 18 & 14 & 12 & 12 & 7 \\
\hline & Neonatal mortality rate & - & - & - & - & - & - & - \\
\hline & Total fertility rate & 1.7 & 1.6 & 1.6 & - & - & - & - \\
\hline \multirow[t]{5}{*}{ Meghalaya } & Birth rate & 24.1 & 24.1 & 23.9 & 24.1 & 23.7 & 23.7 & 22.8 \\
\hline & Death rate & 7.8 & 7.6 & 7.6 & 7.5 & 7.4 & 6.6 & 6.1 \\
\hline & Infant mortality rate & 52 & 49 & 47 & 46 & 42 & 39 & 39 \\
\hline & Neonatal mortality rate & - & - & - & - & - & - & - \\
\hline & Total fertility rate & 2.8 & 2.7 & 2.7 & - & - & - & - \\
\hline \multirow[t]{5}{*}{ Manipur } & Birth rate & 14.4 & 14.6 & 14.7 & 14.6 & 14.4 & 12.9 & *14.6 \\
\hline & Death rate & 4.1 & 4.0 & 4.0 & 4.3 & 4.0 & $* 4.5$ & $* 5.3$ \\
\hline & Infant mortality rate & 11 & 10 & 10 & 11 & 9 & $* 11$ & $* 12$ \\
\hline & Neonatal mortality rate & - & - & - & - & - & - & - \\
\hline & Total fertility rate & 1.5 & 1.5 & 1.5 & - & - & - & - \\
\hline \multirow[t]{5}{*}{ Mizoram } & Birth rate & 16.6 & 16.3 & 16.1 & 16.4 & 16.2 & 15.5 & 15.0 \\
\hline & Death rate & 4.4 & 4.4 & 4.3 & 4.3 & 4.2 & 4.2 & 4.0 \\
\hline & Infant mortality rate & 34 & 35 & 35 & 32 & 32 & 27 & 15 \\
\hline & Neonatal mortality rate & - & - & - & - & - & - & - \\
\hline & Total fertility rate & 1.6 & 1.5 & 1.5 & - & - & - & - \\
\hline \multirow[t]{5}{*}{ Tripura } & Birth rate & 14.3 & 13.9 & 13.7 & 14.9 & 14.7 & 13.7 & 13.0 \\
\hline & Death rate & 5.0 & 4.8 & 4.7 & 4.7 & 5.2 & $* 5.5$ & 5.2 \\
\hline & Infant mortality rate & 29 & 28 & 26 & 21 & 20 & $* 24$ & $* 29$ \\
\hline & Neonatal mortality rate & - & - & - & - & - & - & - \\
\hline & Total fertility rate & 1.4 & 1.3 & 1.3 & - & - & - & - \\
\hline \multirow[t]{5}{*}{ Arunachal Pradesh } & Birth rate & 19.8 & 19.4 & 19.3 & 19.2 & 18.8 & $* 18.9$ & 18.3 \\
\hline & Death rate & 5.8 & 5.8 & 5.8 & *6.6 & 6.0 & $* 6.2$ & 6.1 \\
\hline & Infant mortality rate & 32 & 33 & 32 & 30 & 30 & $* 36$ & $* 42$ \\
\hline & Neonatal mortality rate & - & - & - & - & - & - & - \\
\hline & Total fertility rate & - & - & - & - & - & - & - \\
\hline
\end{tabular}

NOTE: (*highest rate of the vital statistics parameter) 
Suganya. P et.al. Trend analysis of vital statistics in India - a key to improve quality of health care services and infrastructure.

Table 6 shows about the trend analysis of vital statistics in north zone of India.

\begin{tabular}{|c|c|c|c|c|c|c|c|c|c|c|c|c|c|c|}
\hline \multirow[t]{2}{*}{ VITAL STATISTICS } & \multicolumn{7}{|c|}{ RURAL } & \multicolumn{7}{|c|}{ URBAN } \\
\hline & 2011 & 2012 & 2013 & 2014 & 2015 & 2016 & 2017 & 2011 & 2012 & 2013 & 2014 & 2015 & 2016 & 2017 \\
\hline Birth rate & 23.3 & 23.1 & 22.9 & 22.4 & 22.4 & 22.1 & $* 21.8$ & 17.6 & 17.4 & 17.3 & 17.4 & 17.3 & 17.0 & 16.8 \\
\hline Death rate & 7.6 & 7.6 & 7.5 & 7.3 & 7.1 & 6.9 & 6.9 & 5.7 & 5.6 & 5.6 & 5.5 & 5.4 & 5.4 & 5.3 \\
\hline Infant mortality rate & 48 & 46 & 44 & 43 & 41 & 38 & 37 & 29 & 28 & 27 & 26 & 25 & 23 & 23 \\
\hline Neonatal mortality rate & 34 & 33 & 31 & 30 & 29 & 27 & 27 & 17 & 16 & 15 & 15 & 15 & 14 & 14 \\
\hline Total fertility rate & 2.6 & 2.6 & 2.5 & 2.5 & 2.5 & 2.5 & 2.4 & 1.8 & 1.8 & 1.8 & 1.8 & 1.8 & 1.8 & 1.7 \\
\hline
\end{tabular}

Table 7 shows about the year-wise distribution of vital statistics in urban and rural areas of India. The mortality rate, birth rate and total fertility rate was found to be highest in rural areas when compared to urban areas.

TABLE 8: HEALTH CARE EXPENDITURE OF INDIA FROM GROSS DOMESTIC PRODUCT (GDP)

\begin{tabular}{|l|l|l|l|}
\hline S.NO. & YEAR & GDP OF INDIA & HEALTH EXPENDITURE FROM GDP \\
\hline 1. & 2011 & 1.82 lakh crores USD & $1.19 \%$ \\
\hline 2. & 2012 & 1.83 lakh crores USD & $1.2 \%$ \\
\hline 3. & 2013 & 1.86 lakh crores USD & $1.2 \%$ \\
\hline 4. & 2014 & 2.04 lakh crores USD & $1.3 \%$ \\
\hline 5. & 2015 & 2.1 lakh crores USD & $1.3 \%$ \\
\hline 6. & 2016 & 2.27 lakh crores USD & $1.4 \%$ \\
\hline 7. & 2017 & 2.6 lakh crores USD & $1.4 \%$ \\
\hline
\end{tabular}

Table 8 shows about the health care expenditure of India from Gross Domestic Product.

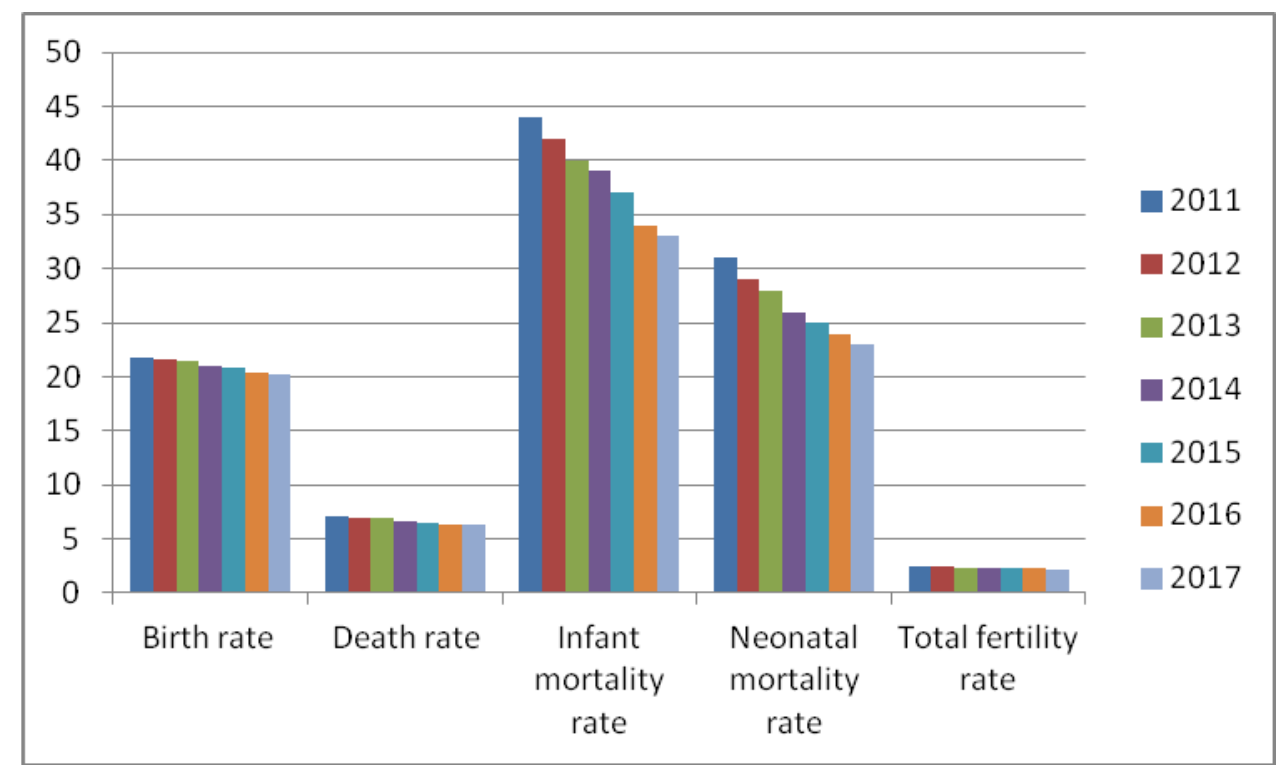

Fig 1: Year-wise distribution of vital statistics in India

\section{DISCUSSION}

The vital statistics is one of the best sources in determining the health care policy and services to be implemented for the welfare of people. The trend analysis of the vital statistics helps the government to provide proper health care programs and planning of public health policies. Hence this present study focused on the trend analysis of vital statistics in India to enhance the quality of health care services in India.

The north zone of India is Jammu and Kashmir, Himachal Pradesh, Punjab, Uttarakhand, Uttar Pradesh, Haryana, Delhi and Chandigarh. Of that the birth rate, death rate, infant mortality rate, neonatal mortality rate was found to be highest in Uttar 
Pradesh. The lowest birth rate was found in Punjab whereas the death was lowest in Delhi. The total fertility rate was highest in Uttar Pradesh and it was lowest in Delhi and Himachal Pradesh among the north zone of India.

The death rate drastically increases in Punjab in the year 2017 this was due to the drug over dosage. Most of the death occurs in Punjab due to the consumption of the overdose of morphine especially in rural areas ${ }^{9}$. To avoid this comprehensive action against drug abuse should be implemented by the government. Dengue fever and cancer is also a major concern for the increased death rate Punjab. This was due to the lack of coordination between local health authorities and the district administration.

The death rate was found to be increased in Jammu and Kashmir in the year 2016. The malnutrition, poor sanitary facilities and violence are the most common cause for increased death rate in Jammu and Kashmir ${ }^{10}$. The government should take appropriate measures and should implement the proper health care facilities and policies for the beneficiaries of the public. The death rate in Himachal Pradesh was found to be increased in the year 2016 when compared to previous year. The malnutrition is the major concern for the increased death rate in Himachal Pradesh. The death rate and neonatal mortality rate gradually increases in Delhi from the year 2015. Heart diseases and iron deficiency anaemia are the major cause for increased death rate in Delhi. This was due to the improper health care services and infrastructure.

The infant mortality rate and death rate was found to be increasing in Uttarakhand and Chandigarh from the year 2015. The insufficient medical facilities were the major root cause for this problem. The shortage of medical manpower in rural and hilly areas causes increase death rate in these states. The government must appoint more doctors in these areas to overcome this situation.
The east zone of India is Bihar, Odisha, Jharkhand and West Bengal. The birth rate and total fertility rate was found to be highest in Bihar whereas the death rate, infant mortality rate and neonatal mortality rate was found to be highest in Odisha. The west Bengal has the lowest birth rate, death rate, infant mortality rate, neonatal mortality rate when compared to the other states in eastern zone of India. The Health \& Family Welfare Department of the State Government has been vested with the responsibility of maintaining and developing the health care system in West Bengal. $80 \%$ of health care services are provided at no cost in this state. This shows the best quality of health care services and the implementation of health care policies in West Bengal ${ }^{11}$.

The neonatal mortality rate gradually increases in Bihar from the year 2015. The neonatal tetanus, pneumonia and meningitis are the major cause of neonatal deaths in Bihar. This can be overcome by ensuring the good quality of health care in both private and private sector with an increasing involvement in the universal health coverage agenda of the Government of India 12 . The death rate was found to be increased in Odisha in the year 2016. This was due to improper health care facilities and manpower in this state.

The west zone of India is Rajasthan, Gujarat, Dadra and Nagar Haveli, Daman and Diu, Maharashtra and Goa. The birth rate, infant mortality rate, neonatal mortality rate and total fertility rate was found to be highest in Rajasthan. The death rate was found to be highest in Gujarat whereas it was lowest in Dadra and Nagar Haveli. Goa shows gradually decrease in mortality rates when compared to other states and union territories this was due to the best medical facilities and the implementation of various advanced programmes in hospitals and thereby providing major health care services in rural areas.

The southern zone of India is Andhra Pradesh, Karnataka, Kerala, Tamil Nadu, Telangana, Lakshadweep, 
Puducherry and Andaman and Nicobar Island. The birth rate was found to be highest in Telangana whereas the death rate was found to be highest in Puducherry. The death rate was found to be lowest in Andaman and Nicobar Island when compared to southern zone of India but the death rate in this state gradually increases from the year 2015. The flu and viral fever are the major cause for the increasing death rate in this region. The government should ensure the health education awareness programs and should develop the health care policies to overcome this condition.

The death rate found to be increase in Tamilnadu in the year 2017. The increased number of deaths occurs due to diabetes, kidney and ischemic heart diseases. The chronic kidney disease is the major cause of increased death rate in this state. The most common risk factor for this disease is increased smoking and alcohol consumption. Tamilnadu is only state that has more number peoples with chronic kidney disease when compared to other state the reason behind this might be due to poor quality and increasing number of alcohol retail shops. Considering the welfare of people, the government of Tamilnadu should take appropriate action in reducing the number of alcohol shops and also ensure proper measure in screening the lifestyle disorders of the people ${ }^{13,14}$. The death rate and infant mortality rate gradually increases in Lakshadweep from the year 2015. The death rate and infant mortality rate was drastically increased in Puducherry in the year 2017. This is due to the poor infrastructure of the hospitals and lack of manpower in rural areas. The death rate found to be increased in Kerala in the year 2016 due to cardiac problems ${ }^{13}$.

The central zone of India is Madhya Pradesh and Chhattisgarh. The birth rate, infant mortality rate, neonatal mortality rate and total fertility rate was found to highest in Madhya Pradesh whereas the death rate was found to be highest in Chhattisgarh in the year 2017. Table 6 shows about the trend analysis of vital statistics north east zone in India. The north east zone is Assam, Sikkim, Nagaland, Meghalaya, Manipur, Mizoram, Tripura and Arunachal Pradesh. The death rate was found to be gradually increased in Nagaland, Manipur and Tripura from the year 2016. The government should take proper appropriate measures in providing the good quality of the health care services to the public. In Arunachal Pradesh, the death rate was found to be increased in the year 2014 and 2017 whereas the infant mortality rate found to be increased from the year 2016. The government should take appropriate measures and should appoint more doctors in rural areas.

The mortality rate, birth rate and total fertility rate was found to be highest in rural areas when compared to urban areas. This indicates that the health care infrastructure was inadequate in rural areas. The government of India should enhance the hospitals facilities in these areas and more doctors should be appointed in primary health centres to obtain beneficiaries for the public. Over all the states and union territories in India Chhattisgarh, Madhya Pradesh, Odisha, Assam, Puducherry, Punjab and Uttar Pradesh have the highest death rate due to inadequate health care facilities and derivation of primary health care infrastructure whereas the Nagaland, Chandigarh and Delhi has the lowest death rate. The infant mortality rate was found to highest in Madhya Pradesh, Assam and Odisha whereas it was lowest in Goa, Manipur and Kerala. The neonatal mortality rate was found to be highest in Madhya Pradesh and Chhattisgarh whereas it was lowest in Kerala, Tamilnadu and Maharashtra. The lowest infant mortality was found in Kerala and Goa. This is because the government has a good quality of services at all health level and focused on the prevention and control of diseases. In Kerala the Primary health centres are converted into family health centres to deliver the effective family centred health services. Goa has the best health and medical care facilities over all states of 
Suganya. P et.al. Trend analysis of vital statistics in India - a key to improve quality of health care services and infrastructure.

India and the majority of health care facilities were available in the rural areas.

The India shows an enormous increase in GDP from the year 2011 but still lacks in attaining the good quality of health. This is because the government spends only a minimum amount for health care. Currently, India ranks fifth place over the entire world in GDP but still there is no improvement in the welfare of people. As we all know that the health is wealth and it is prioritized more than anything in the world hence the government should focus on health care services and increase the health expenditure in the upcoming year for the beneficiaries of people.

The limitations of this study are only data were obtained from the year 20112017. Many data are missing only available data were collected. The current data were not available for the study.

\section{CONCLUSION}

This study will be very useful for the government to plan and develop health care policies in order to improve the health care services in India. Although India ranks fifth place in GDP the government is investing more amount of GDP in various sectors but no measures have been taken to improve the health expenditure. As health of the people prioritized first in the world instead of spending amount in other sectors such as defence forces the government of India can minimize the amount in these sectors and should invest more amount of GDP for health to attain maximum beneficiaries of the people. Since the mortality rates were higher in rural areas the government of India should pay more attention to improve the health care facilities in rural areas by investing more amount of GDP for health care in the forthcoming year for the welfare of people.

\section{Acknowledgement: None}

Conflict of Interest: None

Source of Funding: None

\section{REFERENCES}

1. Population of India 2019. Available from http://statisticstimes.com/demographics/pop ulation-of-india.php on May 3, 2019

2. World health organization. Available from https://www.who.int/

3. Committee Opinion $\mathrm{N}^{\circ}$ 639. The importance of vital records and statistics for the obstetrician-gynecologist. Obstet Gynecol. 2015;126 (03).

4. Sample registration bulletin - census of India. Available from http://censusindia.gov.in/vital_statistics/SRS _Bulletins/SRS_Bulletin-Rate-2017_May_2019.pdf

5. Sample registration bulletin - census of India. Available from

6. http://censusindia.gov.in/vital_statistics/SRS _Bulletins/Bulletins.html on Feb 6, 2020

7. Sample registration bulletin - census of India. Available from http://censusindia.gov.in/vital_statistics/SRS _Bulletins/MMR_Bulletin-2015-17.pdf on November,2019

8. Infant mortality rate India. Available from https://data.gov.in/catalog/infant-mortalityrate-india assessed on 20/8/2018.

9. Sample registration bulletin - census of India. Available from http://censusindia.gov.in/vital_statistics/SRS _Report_2012/1_Contents_2012.pdf assessed on 26th March 2020

10. Sharma B, Arora A, Singh K, Singh H, Kaur $P$. Drug abuse: Uncovering the burden in rural Punjab. Journal of family medicine and primary care. 2017 Jul;6(3):558.

11. Jammu and Kashmir: Disease Burden Profile, 1990-2016. Available from http://www.healthdata.org/sites/default/files/ files/Jammu_and_Kashmir_-

_Disease_Burden_Profile\%5B1\%5D.pdf assessed on $26^{\text {th }}$ March 2020.

12. Health and family welfare. Available from https://www.wb.gov.in/departments-healthand-family-welfare.aspx assessed on 29th March 2020.

13. Dandona R, Kumar GA, Bhattacharya D, Akbar M, Atmavilas Y, Nanda P, Dandona L. Distinct mortality patterns at 0-2 days versus the remaining neonatal period: results from population-based assessment in the Indian state of Bihar. BMC medicine. 2019 Dec 1;17(1):140.

14. Prabhakaran D, Jeemon P, Sharma M, Roth GA, Johnson C, Harikrishnan S, Gupta R, 
Suganya. P et.al. Trend analysis of vital statistics in India - a key to improve quality of health care services and infrastructure.

Pandian JD, Naik N, Roy A, Dhaliwal RS. The changing patterns of cardiovascular diseases and their risk factors in the states of India: the Global Burden of Disease Study 1990-2016. The Lancet Global Health. 2018 Dec 1;6(12):e1339-51.

15. Prabu D, Nirmala S, Bharathwaj V.V, Sunayana Manipal, Rajmohan, Nesa Aurlene. Dental manpower in Tamilnadu state, India and its implications- A systematic trend analysis. International
Journal of Current Research 2018; 10(8) 72713-18.

How to cite this article: Suganya. P, Bharathwaj. V. V, Sindhu. R et.al. Trend analysis of vital statistics in India - a key to improve quality of health care services and infrastructure. International Journal of Research and Review. 2021; 8(11): 217-226. DOI: https://doi.org/10. 52403/ijrr.20211129 